\title{
Hydraulic Transients Induced by Pigging Operation in Pipeline with a Long Slope
}

\author{
Tao Deng, ${ }^{1}$ Jing Gong, ${ }^{1}$ Haihao Wu, ${ }^{1}$ Yu Zhang, ${ }^{2}$ Siqi Zhang, ${ }^{1}$ Qi Lin, ${ }^{1}$ and Huishu Liu' \\ ${ }^{1}$ Beijing Key Laboratory of Urban Oil and Gas Distribution Technology, China University of Petroleum, Beijing 102249, China \\ ${ }^{2}$ South East Asia Pipeline Company Limited, China National Petroleum Corporation, Beijing 100028, China \\ Correspondence should be addressed to Jing Gong; ydgj@cup.edu.cn
}

Received 14 July 2013; Revised 22 August 2013; Accepted 9 September 2013

Academic Editor: Bo Yu

Copyright (c) 2013 Tao Deng et al. This is an open access article distributed under the Creative Commons Attribution License, which permits unrestricted use, distribution, and reproduction in any medium, provided the original work is properly cited.

\begin{abstract}
Pigging in pipelines basically performs operations for five reasons including cleaning the pipe interior, batching or separating dissimilar products, displacement, measurement, and internal inspection. A model has been proposed for the dynamic simulation of the pigging process after water pressure testing in a long slope pipeline. In this study, an attempt has been made to analyze two serious accidents during pigging operation in 2010 by the model which is developed by the method of characteristic (MOC) by Wylie et al. (1993) and the two-phase homogeneous equilibrium vaporous cavitation model deveoped by Shu (2003) for vaporous cavitation. Moreover, simulation results of the third operation show good agreement with field data from the previous field trial. After investigation, it was showed that the impulse pressures produced during collapse of a vapor cavity result in severe damage of tubes.
\end{abstract}

\section{Introduction}

Modern hydraulic systems are widely applied to various industrial fields. Routinely, for pressure testing of segmental pigging, pigs are usually employed to remove liquids and deposits after the pressure testing. Although there are a large number of variations and special applications, pigs are basically utilized in pipelines to perform operations for five reasons including cleaning the pipe interior, batching or separating dissimilar products, displacement, measurement, and internal inspection. Pressure testing, which includes strength tests and tightness tests, is an important part of the guarantee for the safe operation of oil and gas pipelines. As, air is accessible and inexpensive, it was utilized as a medium and the pressure is increased gradually to values that the pressure testing requires. However, operation staffs have difficulty to find quality defects for small spills. For a long pipeline, once a pipeline leakage takes place, pressure would not decrease dramatically due to the compressibility of air. Moreover, there is also the risk of getting pipes burst by pressurized air. Thus, air pressure testing has been out of use since the 1970s. Fortunately, water pressure testing can cover up those problems. The pipelines of thousands of kilometers in length are divided into segments varying in length according to elevation profiles and maximum allowable differences. B 31.8 Code Committee and American Gas Association jointly made great contribution to promote water pressure testing for decades. Pressure testing gradually took advantage of water for its safety and stability. Generally, pigging process is safe under low pressure because after pressure testing, operation staffs will decrease pressure by discharging the water through the valves at the end of pipes. However, due to varying elevation profiles, there are always some segments with a long slope, especially in a mountainous area and pigging operation, that should deal with new problems. More specifically, for full-flow pipes with a long slope, valves opening and moving pigs may cause liquid transients in a pipeline. Pigging process is subject to rapid pressure transients, resulting in water-hammer events.

In a system, any change in flow velocity causes a change of pressure instantaneously. Large pressure variations and distributed cavitation (bubble flow) may be involved due to the sudden shutdown of a pump or closure of a valve. Column separation therefore may occur and may have a significant impact on subsequent transients in the system [1]. 
During the course of a transient, usually at high point, the pressure in a pipeline falls to the vapor pressure of water, resulting in a localized liquid column separation [2-5] or vaporous cavitation. Streeter and Wylie, in their textbooks [4, 6] (Wylie and Streeter 1978a), summarized previous work on column separation in detail. Beuthe [7] provided an extensive general review with emphasis on steam condensation. For vaporous cavitation, vapor is distributed along a portion of a pipeline, rather than being concentrated at one location as for a localized liquid column separation. However, the formation and collapse of a vapor cavity in a pipeline may lead to unexpectedly high pressure rises in the form of short-duration pressure pulses. Angus [8], emphasized that the damage done to pipes as a result of water hammer is so serious that no engineer can afford to neglect it in the design of long pipes, particularly those under low heads. Most of the early efforts in liquid transients in pipelines emphasized particularly on the prediction of the maximum pressure rise due to closure of a valve [9-11] or shutdown of hydropower turbines [12]. Joukowsky's simple water hammer formula is used to determine the maximum head rise due to the instantaneous closure of a valve without consideration of liquid column separation or linepack during a transient event. When a local column separation forms, the pressure magnitude produced by the collapse of the cavity is greater than the Joukowsky rise which is referred to as a shortduration pressure pulse. Previous analytical studies $[8,13-$ 15] predicted that the pressure rise, due to the collapse of a vapor cavity, may exceed the Joukowsky pressure rise. Much previous experimental data showed strong attenuation of the maximum pressure rise upon the first collapse of a cavity at a valve [16-18]. Jaeger et al. [19], Martin [20], and Thorley [21] were devoted to comprehensive bibliographies of the historical development of many aspects of water hammer including column separation. As previously mentioned, column separation is a common approach in transmission line modeling. However, such an approach is oversimplistic and can lead to unrealistic results. Shu [22] proposed the twophase homogeneous equilibrium vaporous cavitation model which could avoid unrealistically high pressure spikes with consideration of frequency-dependent friction.

A pipe is divided in to two parts including the upstream air section and the downstream liquid section by a pig. Because water directly discharges into atmospheric environment, the liquid flow will be under depressurized condition. Additionally, compressed air at upstream is to be at low pressure. In order to ensure that the pig is moving forward, the pressure is just greater than the resisting force acting on the pig. The pig slowly moves and has great influence on the hydrodynamic pressure of the downstream flow. Accordingly, the pressure downstream may drop to or below vapor pressure and it would result in a large cavity of vapor usually at high points. In previous researches [23, 24], cavities were assumed to form only at high points, at changes in pipeline slope (convex up), and at system boundaries. Moreover, the gas and liquid two-phase flow may appear in the sloping pipe where the hydraulic grade line is found to be at or below the elevation of vapor pressure head. Ultimately, sever accident may occur when column separation collapses

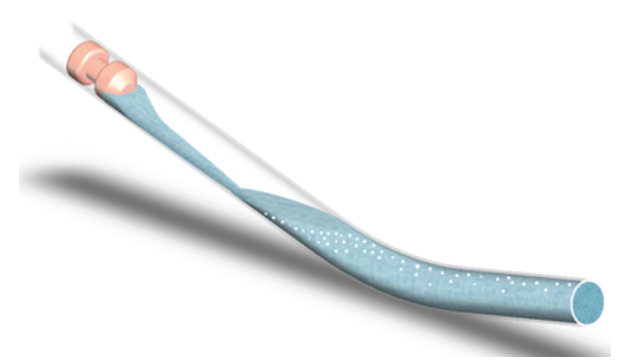

(1)

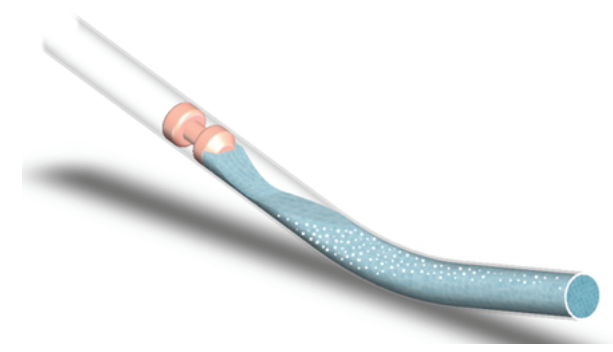

(2)

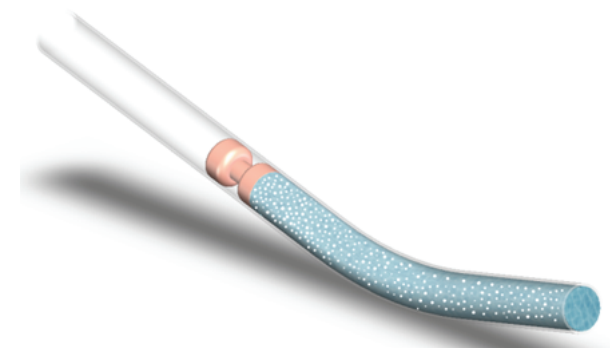

(3)

FIGURE 1: Schematic diagram of collapse of a cavity by a pig.

by the heavy pig at high speed. Due to the factors such as the terrains, a large number of bubbles will be produced, and the flow pattern is the bubbly flow with the intense pressure oscillations at the end of the pipeline. The large cavity of vapor and air between the pig and downstream liquid-filled pipe will be compressed at the downhill when the pig runs fast after the high point. The compression is an isothermal process, and the gas would undergo the extrusion process at the end of the outlet. Eventually the gas is dispersed into water in the form of bubbles as shown in Figure 1.

\section{Mathematical Methods}

2.1. Conventional MOC. One-dimensional continuity and momentum equations are applied to analyze the hydraulic transients. A number of approaches have been introduced for the simulation of the pipeline transients including the method of characteristics (MOC), wave characteristics method (WCM), finite volume method (FVM) [25], finite element method (FEM), and finite difference method (FDM). Among these methods, MOC is extensively used due to its simplicity. It is an explicit method and a powerful tool to analyze hydraulic transients in pipeline flow. With the method of characteristics (MOC), the partial differential equations can be converted into ordinary differential equations. 
The method of characteristics is a technique that takes advantage of the known physical information at each point of the regular rectangular grid. Therefore, the results of physical characteristics can be quickly calculated in every time step.

For a fixed cross-sectional area, the mass conservation equation can be written as follows:

$$
\frac{\partial H}{\partial t}+V \frac{\partial H}{\partial x}+\left(\frac{a^{2}}{g A}\right) \frac{\partial Q}{\partial x}=0 .
$$
by:

The momentum conservation equation can be expressed

$$
\frac{1}{g A}\left(\frac{\partial Q}{\partial t}+V \frac{\partial Q}{\partial x}\right)+\frac{\partial H}{\partial x}+f Q|Q|^{1-m}=0,
$$

where

$$
f=0.0246 \frac{\nu^{m}}{D^{5-m}} .
$$

The MOC approach transforms the above partial differential equations into the ordinary differential equations along the characteristic lines and is defined as

$$
\begin{aligned}
& C^{+}\left\{\begin{array}{l}
\frac{d x}{d t}=V+a \\
\frac{a}{g A} d Q+d H+f Q|Q|^{1-m} a d t=0,
\end{array}\right. \\
& C^{-}\left\{\begin{array}{l}
\frac{d x}{d t}=V-a \\
\frac{a}{g A} d Q-d H+f Q|Q|^{1-m} a d t=0 .
\end{array}\right.
\end{aligned}
$$

Due to the fact that $V \ll a$, the term of $V$ can be omitted from the equations. Flow rate $Q$ is unknown and difficult to determine between time steps $t$ and $t+\Delta t$, because it varies with time and space. Therefore, it is impossible to identify the value of $Q_{P}$. However, the term of $\int_{B}^{P} f Q|Q|^{1-m} d x$ can be dealt with approximately by the method of Streeter and Wylie. So we assume that

$$
\begin{aligned}
& Q|Q|^{1-m}=Q_{P}\left|Q_{A}\right|^{1-m}, \\
& Q|Q|^{1-m}=Q_{P}\left|Q_{B}\right|^{1-m} .
\end{aligned}
$$

Due to the above simplification, these equations are integrated on the characteristic lines between time steps $t$ and $t+\Delta t$, as shown in Figure 2, and solved by the known variables:

$$
\begin{aligned}
& C^{+}:\left\{\begin{array}{l}
\frac{\Delta x}{\Delta t}=+a \\
\frac{a}{g A}\left(Q_{P}-Q_{A}\right)+\left(H_{P}-H_{A}\right)+f Q_{P}\left|Q_{A}\right|^{1-m} a \Delta t=0,
\end{array}\right. \\
& C^{-}:\left\{\begin{array}{l}
\frac{\Delta x}{\Delta t}=-a \\
\frac{a}{g A}\left(Q_{P}-Q_{B}\right)-\left(H_{P}-H_{B}\right)+f Q_{P}\left|Q_{B}\right|^{1-m} a \Delta t=0 .
\end{array}\right.
\end{aligned}
$$

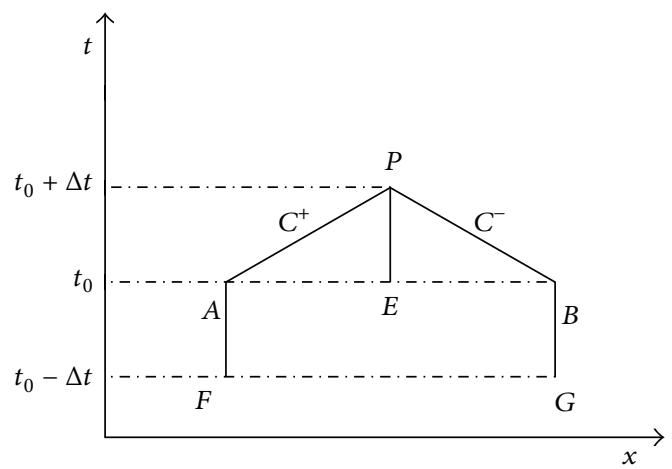

FIgURE 2: Characteristic lines in $x$-t plan.

These equations can be written in the simplified forms as follows:

$$
\begin{aligned}
& C^{+}: H_{P}=R_{A}-S_{A} Q_{P}, \\
& C^{-}: H_{P}=R_{B}+S_{B} Q_{P},
\end{aligned}
$$

where

$$
\begin{gathered}
R_{A}=H_{A}+C_{W} Q_{A}, \\
R_{B}=H_{B}-C_{W} Q_{B}, \\
S_{A}=C_{W}+f\left|Q_{A}\right|^{1-m} a \Delta t, \\
S_{B}=C_{W}+f\left|Q_{B}\right|^{1-m} a \Delta t, \\
C_{W}=\frac{a}{g A},
\end{gathered}
$$

where the $Q_{P}$ is unknown flow at point $P$ at time $t+\Delta t, H_{P}$ is the unknown hydraulic head at point $P$ at time $t+\Delta t, Q_{A}$ and $Q_{B}$ are flows at neighboring sections of $P$ at the previous time $t$, and $H_{A}$ and $H_{B}$ are heads at neighboring sections of $P$ at the previous time $t$.

2.2. The Two-Phase Homogeneous Equilibrium Vaporous Cavitation. When vaporous cavities are locally incipient, the local pressures may be less than or greater than the vapor pressure of the liquid. However, for modeling purposes in engineering, it is assumed that the local pressures are equal to the vapor pressure when vaporous cavitation is occurring. During the pigging process, vaporization occurs and vapor cavities may be physically dispersed homogeneously in the form of bubbles. Due to the factors such as the terrains, a large number of bubbles will be produced, and the flow pattern is the bubbly flow with the intense pressure oscillations along the pipeline. The behavior of the flow should be described by the two-phase flow theory. Otherwise, water hammer equations solved by the MOC can be adopted for the singlephase flow. 
The basic equations for the unsteady homogeneous equilibrium flow model in a tube are

$$
\begin{gathered}
\frac{1}{a^{2}} \frac{\partial P}{\partial t}+\left(\rho_{l}-\rho_{v}\right) \frac{\partial \alpha}{\partial t}+\frac{\rho_{m}}{\pi r_{0}^{2}} \frac{\partial}{\partial x}\left(\frac{Q}{\alpha}\right)=0 \\
\frac{\rho_{m}}{\pi r_{0}^{2}} \frac{\partial}{\partial t}\left(\frac{Q}{\alpha}\right)+\frac{\partial P}{\partial x}+F_{0}\left(\frac{Q}{\alpha}, \alpha\right)+\rho_{m} g \sin \theta_{0}=0
\end{gathered}
$$

In terms of the volumetric fraction $\alpha$ of liquid and vapor phase density $\rho_{v}$, the mean density $\rho_{m}$ can be written as

$$
\rho_{m}=\alpha \rho_{l}+(1-\alpha) \rho_{v}
$$

In the above equations, the second term in (9) describes the interfacial mass transfer rate and the term $Q / \alpha$ in (9), and (11) shows the flow rate differences between the liquid and the vapor phase. Using the Darcy-Weisbach friction factor $f$, the term $F_{0}(Q / \alpha, \alpha)$ can be expressed as follows:

$$
F_{0}\left(\frac{Q}{\alpha}, \alpha\right)=\frac{f \rho_{m} Q|Q|}{4 \pi^{2} \alpha^{2} r_{0}^{5}}
$$

The method of characteristics is used to transform the above equations to four ordinary differential equations:

$$
\begin{aligned}
& C^{+}:\left\{\begin{array}{l}
\frac{1}{\pi r_{o}^{2}} \frac{d}{d t}\left(\frac{Q}{\alpha}\right)+\frac{1}{\rho_{l} a} \frac{d}{d t}\left(P-p_{v}\right)+a \frac{\partial}{\partial t}\left(\ln \frac{\rho_{m}}{\rho_{l}}\right) \\
+\frac{f Q|Q|}{4 \pi^{2} \alpha^{2} r_{0}^{5}}+g \sin \theta_{0}=0 \\
\frac{d x}{d t}=a,
\end{array}\right. \\
& C^{-}:\left\{\begin{array}{l}
\frac{1}{\pi r_{o}^{2}} \frac{d}{d t}\left(\frac{Q}{\alpha}\right)-\frac{1}{\rho_{l} a} \frac{d}{d t}\left(P-p_{v}\right)-a \frac{\partial}{\partial t}\left(\ln \frac{\rho_{m}}{\rho_{l}}\right) \\
+\frac{f Q|Q|}{4 \pi^{2} \alpha^{2} r_{0}^{5}}+g \sin \theta_{0}=0 \\
\frac{d x}{d t}=-a .
\end{array}\right.
\end{aligned}
$$

The equations needed to solve the variables at each time step are

$$
\begin{aligned}
& C^{+}: \frac{1}{\pi r_{0}^{2}} \frac{Q_{p}}{\alpha_{p}}+\frac{1}{\rho_{l} a}\left(P_{p}-P_{V}\right)+\frac{a}{2} \ln \frac{\rho_{m p}}{\rho_{l}}=C_{A}, \\
& C^{-}: \frac{1}{\pi r_{0}^{2}} \frac{Q_{p}}{\alpha_{p}}-\frac{1}{\rho_{l} a}\left(P_{p}-P_{V}\right)-\frac{a}{2} \ln \frac{\rho_{m p}}{\rho_{l}}=C_{B},
\end{aligned}
$$

where $Q_{p}, P_{p}$, and $\alpha_{D}=\left(\rho_{m D}-\rho_{V}\right) /\left(\rho_{l}-\rho_{v}\right)$ can be solved by the above equations, $C_{A}$ and $C_{B}$ are constant:

$$
\begin{aligned}
C_{A}= & \frac{1}{\pi r_{0}^{2}}\left(\frac{Q_{A}}{\alpha_{A}}\right)+\frac{1}{\rho_{l} a}\left(P_{A}-P_{V}\right)+\frac{a}{2} \ln \frac{\rho_{m E} \rho_{m F}}{\rho_{l} \rho_{m A}} \\
& -\frac{f \Delta x Q_{A}\left|Q_{A}\right|}{4 \pi^{2} \alpha_{A}^{2} r_{0}^{5} a}-\frac{g \Delta x \sin \theta_{0}}{a}, \\
C_{B}= & \frac{1}{\pi r_{0}^{2}}\left(\frac{Q_{B}}{\alpha_{B}}\right)+\frac{1}{\rho_{l} a}\left(P_{B}-P_{V}\right)+\frac{a}{2} \ln \frac{\rho_{m E} \rho_{m G}}{\rho_{l} \rho_{m B}} \\
& -\frac{f \Delta x Q_{B}\left|Q_{B}\right|}{4 \pi^{2} \alpha_{B}^{2} r_{0}^{5} a}-\frac{g \Delta x \sin \theta_{0}}{a},
\end{aligned}
$$

The two-phase homogeneous equilibrium vaporous cavitation model has no conflict between negative cavity sizes and pressures below the vapor pressure.

If $C_{A} \geq C_{B}$, then $\alpha_{p}=1$,

$$
P_{p}=\frac{\rho_{l} a}{2}\left(C_{A}-C_{B}\right)+P_{V}
$$

If $C_{A}<C_{B}, P_{p}=P_{V}$, then

$$
\alpha_{p}=\frac{\rho_{l} \exp \left(\left(C_{A}-C_{B}\right) / a\right)-\rho_{v}}{\rho_{l}-\rho_{V}} .
$$

In either case,

$$
Q_{p}=\frac{\pi r_{0}^{2} \alpha_{p}}{2}\left(C_{A}+C_{B}\right)
$$

Numerical results show that the volume rate range is from 0 to $0.95 \mathrm{~m}^{3} / \mathrm{s}$. According to the present study, $\rho_{l}=$ $1000 \mathrm{~kg} / \mathrm{m}^{3}, \rho_{v}=1.293 \mathrm{~kg} / \mathrm{m}^{3}, a=1100 \mathrm{~m} / \mathrm{s}, A=1.099 \mathrm{~m}^{2}$, $\theta_{0} \approx 0, f=0.00035, P_{V}=2340 \mathrm{~Pa}$, and $\Delta x=110 \mathrm{~m}$ are given; then we assume that the volumetric fraction of liquid $\alpha$ varies between 0.999 and 0.5 . Therefore, it is possible to identify the values of $C_{A}$ and $C_{B}$ by our program, and the range is from $-380.837 \mathrm{~m} / \mathrm{s}$ to 22.864 in the present study.

2.3. Boundary Conditions. Boundaries include the inlet of pipeline, the outlet of pipeline, the tail of the pig, and nose of the pig. In order to solve the flow dynamic equations, boundaries conditions must be given. Boundaries at the pipeline inlet and outlet are constant flow rate and constant pressure, respectively. In addition, it is assumed that pressure and flow rate at the tail of the pig are the same as they are in the upstream fluid, close to the pig. We assume that the pig is a moving boundary with no thickness compared with the length of the pipeline, but its weight would be considered. Based on the above assumptions, the behavior of the pig is taken into account to solve the flow dynamics equations.

The behavior of the pig in the pipeline is determined by a balance of forces acting on the pig as shown in Figure 3. The pig will move forward if the drag force is less than the driving force, but it will stop when the drag force is dominant:

$$
P_{1}=P_{2}+\Delta P_{s}+\frac{1}{A} M \cdot g \cdot \sin \theta_{0}+\frac{M}{A} \frac{d V}{d t},
$$




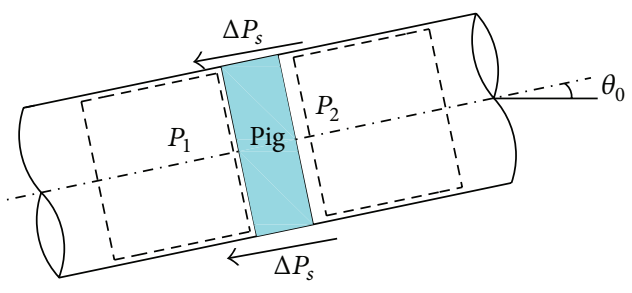

Figure 3: Forces acting on the pig.

TABLE 1: Summary of basic parameters for field operations.

\begin{tabular}{ll}
\hline Parameters & Values \\
\hline The length of pipeline & $6.93 \mathrm{Km}$ \\
Pipe size & $\Phi 1219 \times 18.4 \mathrm{~mm}$ \\
The maximum elevation difference & $178.5 \mathrm{~m}$ \\
Wall equivalent roughness & $0.01 \mathrm{~mm}$ \\
Mass of pig & $700.0 \mathrm{~kg}$ \\
Frictional resistance between pig and pipe wall $0.03 \mathrm{MPa}$ \\
Static friction resistance between pig and pipe & $0.04 \mathrm{MPa}$ \\
wall & $\mathrm{XHP} 1070$ \\
Type of compressor & $2.2 \mathrm{MPa}$ \\
Rated operating pressure & $30.0 \mathrm{Nm}{ }^{3} / \mathrm{min}^{2}$ \\
Air displacement &
\end{tabular}

where $V, M, P_{1}, P$, and $\theta_{0}$ are the pig velocity, pig mass, the pressure on the upstream, downstream faces of the pig, and angle between axis and horizontal direction. Term $\Delta P_{s}$ represents the axial contact force between the pig and the pipe wall, acting in opposition to the pig motion, in the direction of the pig axis. The axial contact force between the pig and the pipe wall is obtained from the contact force equation.

\section{Results and Discussion}

For the convenience of analysis, the main stages (labeled with roughness of back line in Figure 4) of the pigging process are defined as follows, according to the pig position during the process:

(1) the pig flat-segment movement stag,

(2) the pig gully-segment movement stage,

(3) the pig downhill-segment movement stage,

(4) the pig near outlet-segment movement and overpressure stage.

As shown in Figure 4, the pipeline with a long slope is nearly 7 kilometers long and 1219 millimeters in diameter. Air compressors and a valve were installed at the high point and the low point, respectively. A pig was put into pipeline from the high point before air compressors started to work to make the pig move and drain away water at the low point.

Table 1 summarizes some important information of the pigging process in practice including pipeline, pig, and air compressor.
TABLE 2: Summary of two accidents.

\begin{tabular}{lcc}
\hline & $\begin{array}{c}\text { The first } \\
\text { accident }\end{array}$ & $\begin{array}{c}\text { The second } \\
\text { accident }\end{array}$ \\
\hline Number of compressor & 2 & 1 \\
Total time of pigging process & 20 Hours & 39.5 Hours \\
The length of drainage pipe & $150.0 \mathrm{~m}$ & $150.0 \mathrm{~m}$ \\
The drainage pipe size & $\Phi 159.0 \times$ & $\Phi 159.0 \times$ \\
The length of rupture & $8.7 \mathrm{~mm}$ & $8.7 \mathrm{~mm}$ \\
Maximum of air pressure & $2.6 \mathrm{~m}$ & $2.5 \mathrm{~m}$ \\
Bursting pressure of tube & $20.83 \mathrm{MPa}$ & $1.01 \mathrm{MPa}$ \\
\hline
\end{tabular}

\subsection{Numerical Simulation of Two Accidents}

3.1.1. The First Accident Description. On July 19, a couple of XHP1070 air compressors and a DN150 valve were installed for dewatering after water pressure testing. All the preparations for the pigging process were completed and the pig was put in the pipeline. At nine oclock in the morning, the compressors started to work and the valve was simultaneously opened. At five o'clock in the next morning, an eruption of the mixture of water and gas occurred at the outlet of the pipeline, and the pigging operation had taken nearly twenty hours. Finally, a fracture of $2.6 \mathrm{~m}$ in length was found at the last piece of steel tube.

3.1.2. The Second Accident Description. On September 21, an air compressor and a DN150 valve were installed for dewatering after water pressure testing. At three oclock in the morning, a pig was put in the pipe before the compressor started to work, while the valve was opened. At half past six in the next afternoon, the second accident happened, and a fracture of $2.5 \mathrm{~m}$ in length was about $5 \mathrm{~m}$ away from the first fracture. The pigging operation had totally taken nearly thirty nine hours and half an hour. During this period of time, according to the records, the maximum of air pressure was about 1.01 MPa.

After investigation, however, the tubes have no quality default, and the rated operating pressure of the air compressor is $2.2 \mathrm{MPa}$ so that the compressed air unlikely caused the damages. Additionally, bursting pressure is determined from Barlow's equation that instantaneous pressure for severe rupture of the tube should be over $20.83 \mathrm{MPa}$ as shown in Table 2.

A mathematical model has been suggested for simulating the pigging process, based on our own previous work. Meanwhile, these results were obtained from simulating the process by our own program.

The simulated time of the first pigging operation was 19.6 hours. During the pig downhill-segment movement stage, some amount of water was gathered in the part of low elevation near the outlet due to the gravity. When the pig was close to the end of the pipe, some amount of gas downstream would undergo extrusion process and eventually was dispersed into water as shown in Figure 1. Consequently, the gas cavity collapsed resulting in an impulse pressure up 


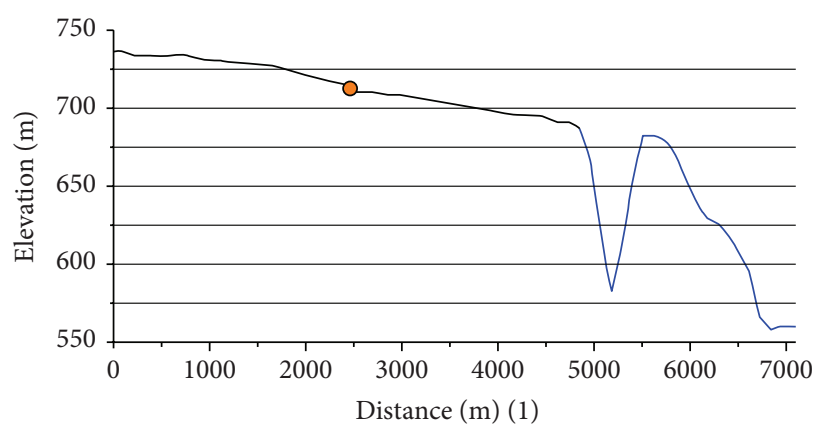

(a)

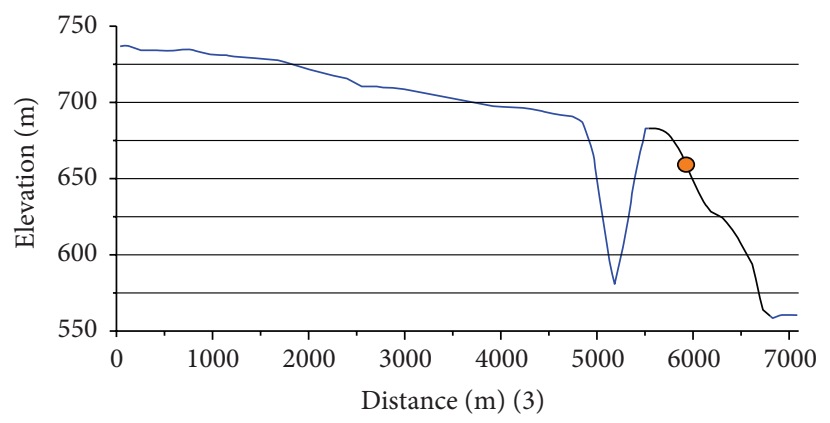

(c)

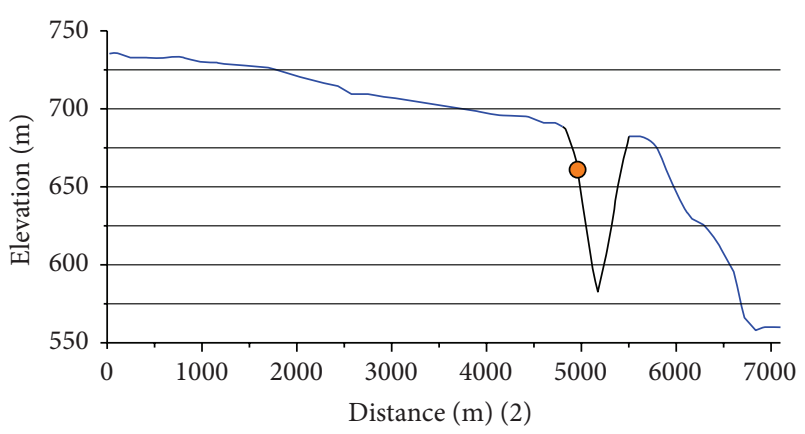

(b)

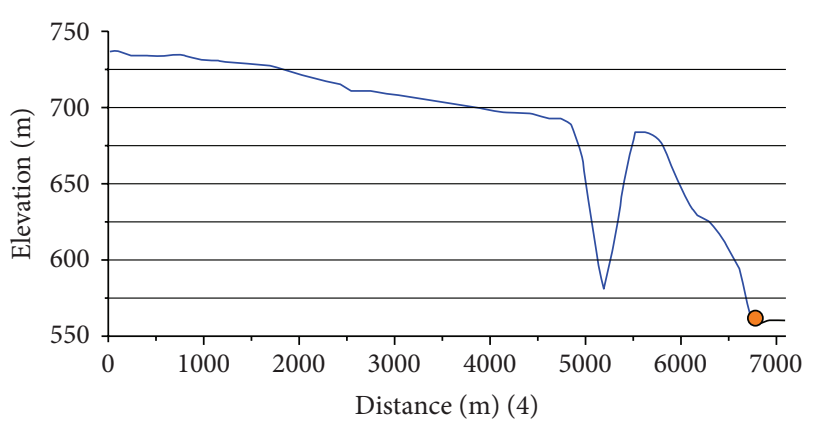

(d)

FIGURE 4: Four stages for pigging process.

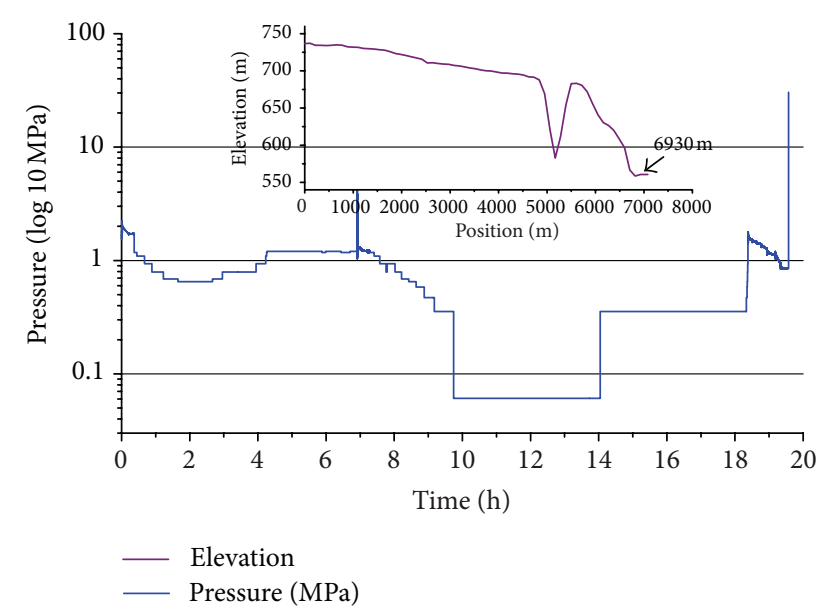

FIgURE 5: Numerical result of pressure at the end of pipe for the first accident.

to $30.50 \mathrm{MPa}$ as shown in Figure 5. The value of the impulse pressure is larger than the bursting pressure of the tube, and therefore it caused the rupture.

There is a large slope at the end of pipe so that pressure varied with the liquid level in the pipe. In other words, pressure would decrease when the liquid level dropped, and pressure would increase when the liquid level rose. According to the results, the liquid level quickly dropped near $9 \mathrm{~h}$ and $28 \mathrm{~h}$, and the liquid level rose near $11 \mathrm{~h}$ because the flow rate of outlet and top was varying during the pigging process. The flow rate at the outlet was much larger than that at the top

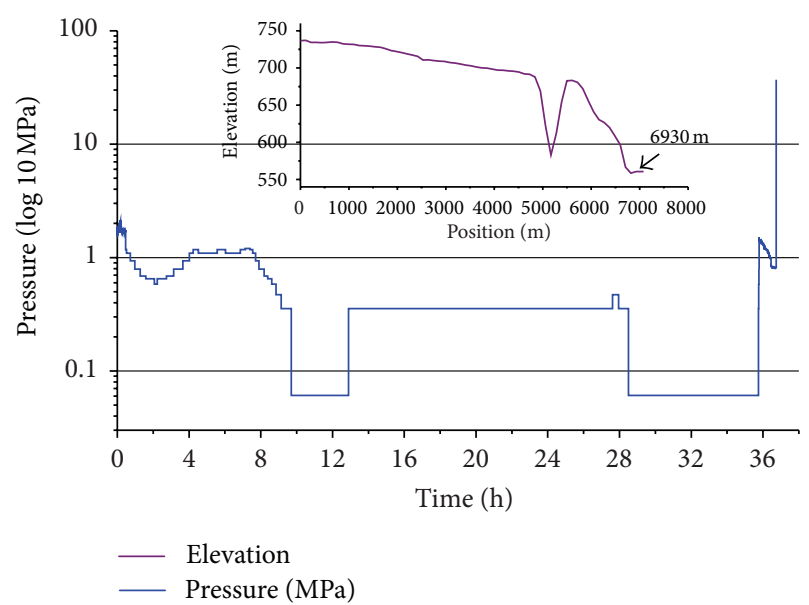

FIGURE 6: Numerical result of pressure at the end of pipe for the second accident.

when the liquid level quickly dropped. On the contrary, the flow rate of top was much larger than that at the outlet when the liquid level quickly rose.

The simulated time of the first pigging operation was 19.6 hours. During this period of time, the maximum pressure of compressed air was as much as $1.03 \mathrm{MPa}$ as shown in Figure 7. Finally, the gas cavity collapsed resulting in an impulse pressure up to $37.03 \mathrm{MPa}$ as shown in Figure 6. The value of the impulse pressure is also larger than the bursting pressure of the tube, and the second accident occurred as shown in Table 3. 
TABLE 3: Summary of numerical simulation of the two accidents.

\begin{tabular}{lcc}
\hline & $\begin{array}{c}\text { The first } \\
\text { accident }\end{array}$ & $\begin{array}{c}\text { The second } \\
\text { accident }\end{array}$ \\
\hline $\begin{array}{l}\text { Number of compressor } \\
\text { Total time of pigging process }\end{array}$ & 2 & 1 \\
Maximum of air pressure & $19.6 \mathrm{Hours}$ & $36.7 \mathrm{Hours}$ \\
Maximum of outlet pressure & $30.50 \mathrm{MPa}$ & $1.03 \mathrm{MPa}$ \\
Bursting pressure & $20.83 \mathrm{MPa}$ & $20.03 \mathrm{MPa}$ \\
\hline
\end{tabular}

TABLE 4: Summary of the field trial and numerical simulation.

\begin{tabular}{lcc}
\hline & The field trial & $\begin{array}{c}\text { Numerical } \\
\text { simulation }\end{array}$ \\
\hline Number of compressor & 1 & 1 \\
Total time of pigging process & $36 \mathrm{Hours}$ & $35.5 \mathrm{Hours}$ \\
Value of the impulse pressure & $1.576 \mathrm{MPa}$ & $1.51 \mathrm{MPa}$ \\
Bursting pressure & $20.83 \mathrm{MPa}$ & $20.83 \mathrm{MPa}$ \\
\hline
\end{tabular}

3.2. Comparison of Field Results to Simulating Predictions. To study the variation of outlet pressure due to the pigging process, a field trial was conducted in 2011 by Luo [26] from China National Petroleum Corporation (CNPC). After two accidents, the third operation was conducted and transient pressures were recorded by two pressure transducers which were installed at the third and fourth tubes from the end, respectively. In this experiment, the NS-B pressure transducers are $50 \mathrm{MPa}$ in measurement range and $0.3 \%$ in precision installed with an angle of 90 degrees to assure the results validity. While the drainage tube is $159 \mathrm{~mm}$ in diameter for the first two pigging processes, the last tube of pipe which is $1219 \mathrm{~mm}$ in diameter has four bores of $600 \mathrm{~mm}$ in diameter for drainage, and the total area of the cross sections of the four bores will be equal to the area of the cross section of the tube.

As Figure 8 and Figure 9 show, the simulated time of the first pigging operation was 19.6 hours, and the maximum pressure was as much as $1.51 \mathrm{MPa}$. However, the pressure at the end was constantly kept in lower level for most of the time. Because the pressure at the location of cavitation is usually below the saturated vapor pressure, the vapor pressure of the liquid is adopted as the cavitation inception pressure in this mathematical model for transient cavitation. When the pressure is under the saturated vapor pressure, the water would change into vapor. Furthermore, as it was below the vapor pressure for a long period of time, the air dissolved in the water is released, and thus there would be a large cavity of the water vapor and air. When the pig was close to the end of the pipe, some amount of gas downstream would undergo extrusion process, and eventually an eruption of the mixture of water and gas appeared at the outlet according to field records.

With comparison between model prediction and field data, it was found that the amplitudes of the impulse pressures induced by the collapse of the cavity were nearly the same, and their total time was 36 hours, and 35.5 hours (see Figure 10) respectively as shown in Table 4 .

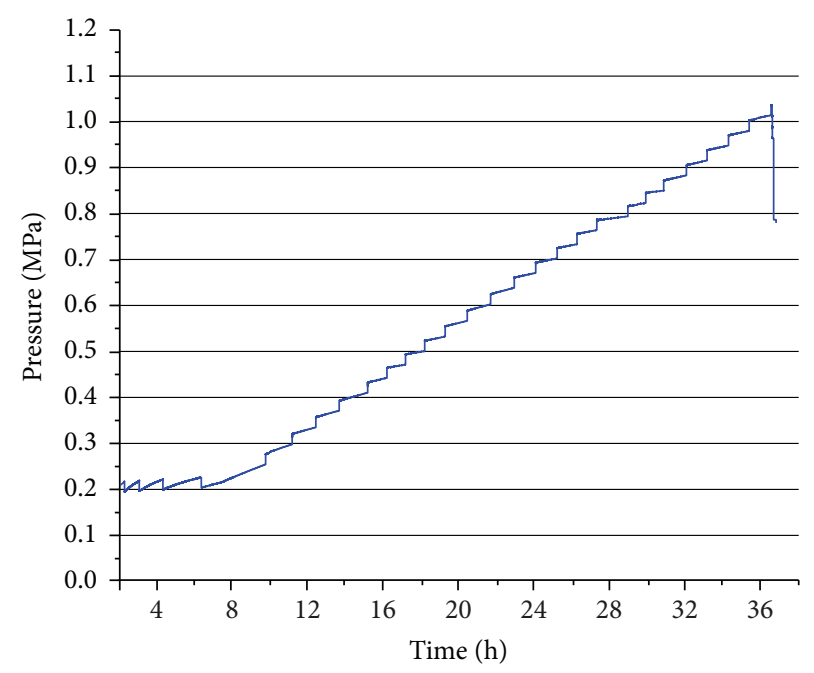

FIgURE 7: Numerical result of air pressure for the second accident.

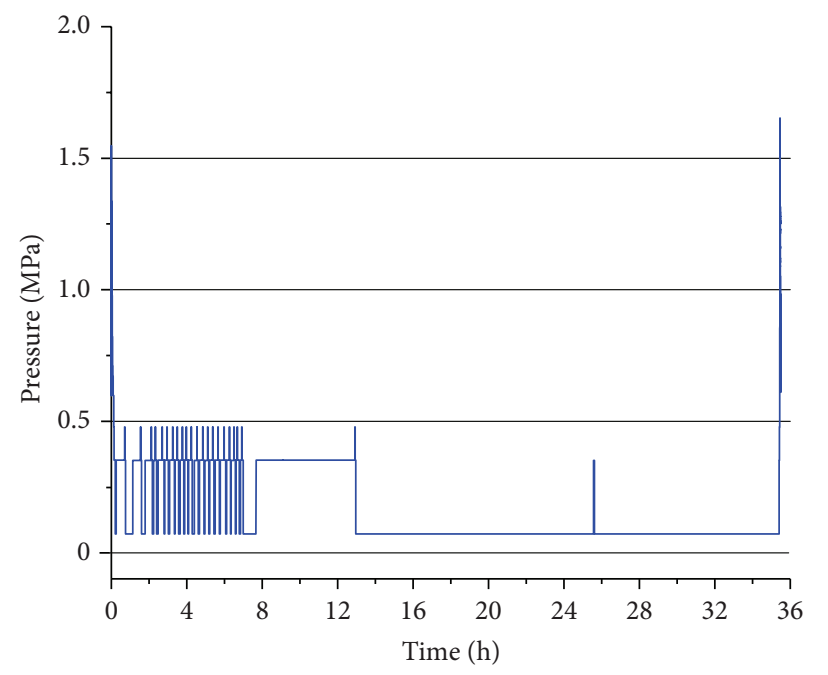

FIGURE 8: Numerical result of pressure at the end of pipe for the field trial.

\section{Conclusions}

The model proposed for the pigging process was employed to understand the flow dynamics in the pipeline and to obtain transient pressures for the two accidents and the field trial. The large cavity of water vapor and air was in the downslope pipe following the peak and slack line flow that exited for a long period of time. When the pig was close to the outlet, the cavity was compressed, and gas underwent the extrusion process and eventually was dispersed into water in the form of bubbles. Finally, the cavity collapsed by the pig, and the serious collision resulted in considerable impulse pressures. The results of the simulation illustrate that the impulse pressures caused the severe damages during the pigging process. Additionally, our model predictions for the third operation showed good agreement with field data, and the diameter of drainage had a significant effect on impulse 


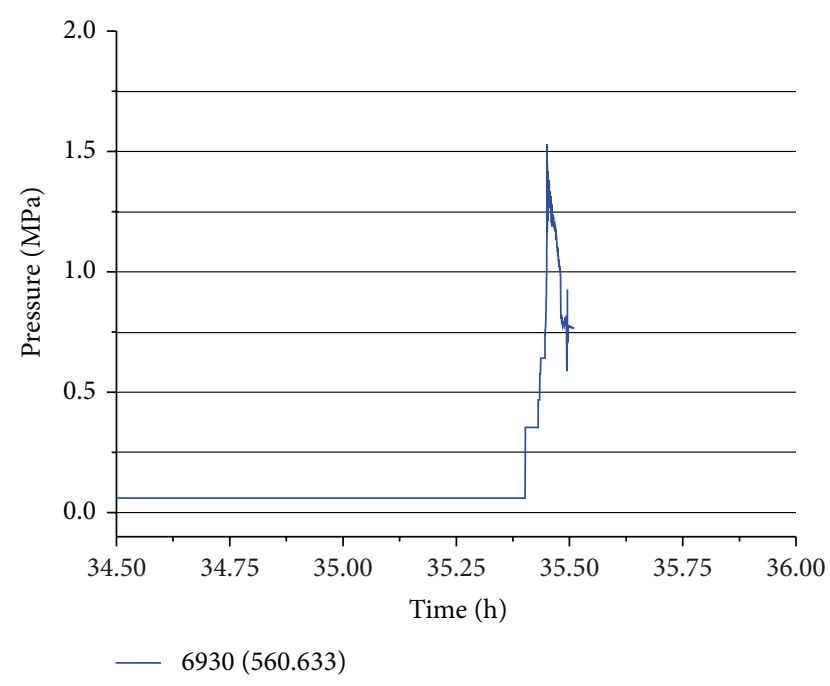

FIGURE 9: Numerical result of the impulse pressure for the field trial.

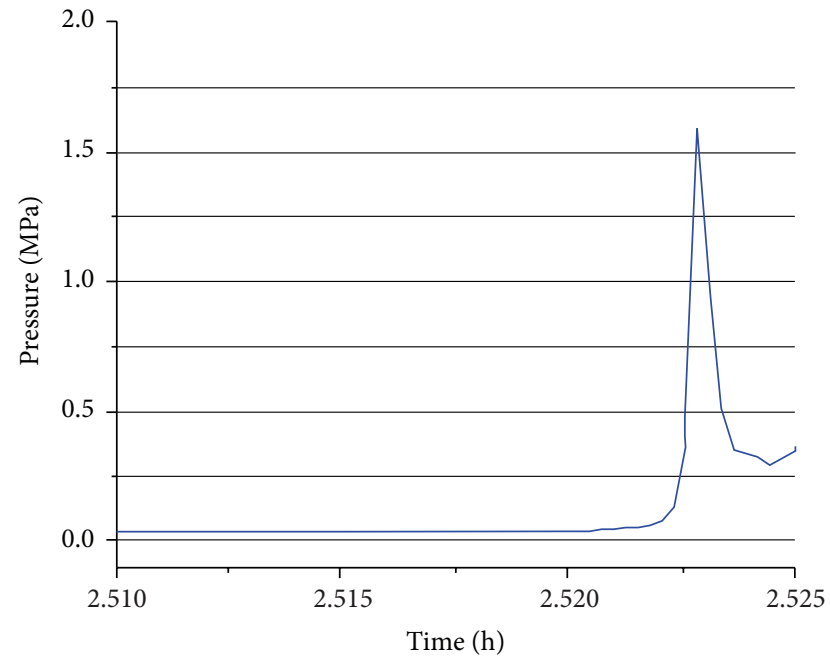

FIgURE 10: Result of the impulse pressure for the field trial.

pressures. Generally, the terrain of pipeline is a key factor for the liquid-fill flow behavior, and slack line flow may appear in a long-slope pipeline. Then, column separation would occur as a common phenomenon for a hilly pipeline, and it can cause devastating effects such as severe damages. Therefore, preventive measures are of a critical significance for practical reasons.

\section{Nomenclature}

$f$ : Friction factor

$x$ : Distance along the pipeline $(\mathrm{m})$

$g$ : Gravity acceleration $\left(\mathrm{m} \cdot \mathrm{s}^{-2}\right)$

$t$ : Time (s)

A: Cross-section area of pipeline $\left(\mathrm{m}^{2}\right)$

$m$ : The index number of Darcy formula

$H$ : Water head of fluid $(\mathrm{m})$

a: Acoustic speed of fluid $(\mathrm{m} / \mathrm{s})$
Q: $\quad$ Volume rate of fluid $\left(\mathrm{m}^{3} / \mathrm{s}\right)$

$Q_{A}, Q_{B}$ : Volume rates for given points $\left(\mathrm{m}^{3} / \mathrm{s}\right)$

$H_{A}, H_{B}$ : Water heads for given points (m)

$Q_{P}: \quad$ Volume rate for unknown point $\left(\mathrm{m}^{3} / \mathrm{s}\right)$

$H_{P}$ : Volume rate for unknown point (m)

$V: \quad$ Velocity $(\mathrm{m} / \mathrm{s})$

D: $\quad$ Diameter of the pipeline $(\mathrm{mm})$

$v: \quad$ Kinematic viscosity of liquid $\left(\left(\mathrm{m}^{2} / \mathrm{s}\right)\right)$

$P_{V}: \quad$ Saturated vapor pressure at liquid temperature $(\mathrm{Pa})$

$\rho: \quad$ Density of liquid $\left(\mathrm{kg} / \mathrm{m}^{3}\right)$

$M: \quad$ Pig mass $(\mathrm{kg})$

$P_{1}$ : The pressure on the upstream faces of the pig $(\mathrm{Pa})$

$P_{2}$ : The pressure on the downstream faces of the pig $(\mathrm{Pa})$

$\beta$ : $\quad$ A angle between axis and horizontal direction (rad)

$\Delta P_{s}: \quad$ The axial contact force $(\mathrm{Pa})$

$\alpha: \quad$ The volumetric fraction of liquid

$\rho_{v}: \quad$ Vapor phase density $\left(\mathrm{kg} / \mathrm{m}^{3}\right)$

$\rho_{l}: \quad$ Liquid phase density $\left(\mathrm{kg} / \mathrm{m}^{3}\right)$

$\rho_{m}: \quad$ The mean density $\left(\mathrm{kg} / \mathrm{m}^{3}\right)$.

\section{Abbreviations}

MOC: The method of characteristic

IAHR: International Association For Hydraulic Research HC: Hydrodynamic cavitation.

\section{Acknowledgments}

The authors thank the National Science \& Technology Specific Project (Grant no. 2011ZX05039-002), and the Key National Science and Technology Specific Project (2011ZX05026-004-03), the National Natural Science Foundation of China (51104167) for their financial support.

\section{References}

[1] A. Bergant, A. R. Simpson, and A. S. Tijsseling, "Water hammer with column separation: a historical review," Journal of Fluids and Structures, vol. 22, no. 2, pp. 135-171, 2006.

[2] R. A. Baltzer, A study of column separation accompanying transient flow of liquid in pipes [Ph.D. thesis], The University of Michigan, Ann Arbor, Mich, USA, 1967.

[3] R. A. Baltzer, "Column separation accompanying liquid transients in pipes," ASME Journal of Basic Engineering D, vol. 89, pp. 837-846, 1967.

[4] V. L. Streeter and E. B. Wylie, Hydraulic Transients, McGrawHill Book Company, New York, NY, USA, 1967.

[5] J. A. Swaffield, "A study of column separation following valve closure in a pipeline carrying aviation kerosine," Proceedings of the Institution of Mechanical Engineers, vol. 184, no. 7, pp. 57-64, 1969.

[6] E. B. Wylie, V. L. Streeter, and L. SuoJones, Fluid Transients in Systems, chapter 3, Prentice Hall, Enalewood Cliffs, NJ, USA, 1993. 
[7] T. G. Beuthe, "Review of two-phase water hammer," in Proceedings of the 18th Canadian Nuclear Society Conference, p. 20, Toronto, Canada, 1997.

[8] R. W. Angus, "Simple graphical solution for pressure rise in pipes and discharge lines," Journal of Engineering Institute of Canada, vol. 18, no. 2, pp. 72-81, 1935.

[9] N. E. Joukowsky, "Water Hammer," Proceedings of the American Water Works Association, vol. 24, pp. 314-424, 1904.

[10] L. Allievi, General Theory of Perturbed Flow of Water in Pressure Conduits, Annali della Societa degli Ingegneri ed architetti italiani, Milano, Italy, 1903.

[11] L. Allievi, Theory of Water Hammer. Notes I to V, ASME, New York, NY, USA, 1913.

[12] N. R. Gibson, "Pressure in penstocks caused by gradual closing of turbine gate," Transactions of the American Society of Civil Engineers, vol. 83, pp. 707-775, 1919.

[13] R. W. Angus, "Water hammer in pipes, includin those supplied by centrifugal pumps: graphical treatment," Proceedings of the Institution of Mechanical Engineers, vol. 136, pp. 245-331, 1937.

[14] I. C. O'Neill, Water Hammer in Simple Pipe Systems [M.S. thesis], Department of civil Engineering, University of Melbourne, Victoria, Australia, 1959.

[15] A. R. Simpson and E. B. Wylie, "Problems encountered in modeling vapor column separation," in Proceedings of the Symposium on Fluid Transients in Fluid-Structure Interaction, pp. 103-107, ASME, Miami Beach, Fla, USA, November 1985.

[16] J. P. Kalkwijk and C. Kranenburg, "Cavitation in horizontal pipelines due to water hammer," ASCE Journal of the Hydraulics Divsion, vol. 97, no. 10, pp. 1585-1605, 1971.

[17] C. Kranenburg, "Transient cavitation in pipelines," Report 73-2, Laboratory of Fluid Mechanics, Communications on Hydraulics, Department of Civil Engineering, Delft University of Technology, 1973.

[18] C. Kranenburg, "Gas release during transient cavitation in pipes," ASCE Jouranl of the Hydraulic Division, vol. 100, no. 10, pp. 1383-1398, 1974.

[19] C. Jaeger, L. S. Kerr, and E. B. Wylie, "Selected bibliography," in Proceedings of the International Symposium on Water Hammer in Pumped Storage Projects, ASME Winter Annual Meeting, pp. 233-241, Chicago, ILL, USA, 1965.

[20] C. S. Martin, "Status of fluid transients in W estern Europe and the United Kingdom: report on laboratory visits by Freeman scholar," ASME Journal of Fluids Engineering, vol. 95, pp. 301318, 1973.

[21] A. R. D. Thorley, A Survey of Investigations into Pressure Surge Phenomena, The City University, Department of Mechanical Engineering, London, UK, 1976.

[22] J.-J. Shu, "Modelling vaporous cavitation on fluid transients," International Journal of Pressure Vessels and Piping, vol. 80, no. 3, pp. 187-195, 2003.

[23] C. Kranenburg, "The effect of gas release on column separation," Report 74-3, Delft University of Technology, Department of Civil Engineering, 1974, Communication on Hydraulics.

[24] V. L. Streeter, “Transient cavitation pipe flow," ASCE Journal of Hydraulic Engineering, vol. 109, no. 11, pp. 1407-1423, 1983.

[25] M. H. Afshar and M. Rohani, "Water hammer simulation by implicit method of characteristic," International Journal of Pressure Vessels and Piping, vol. 85, no. 12, pp. 851-859, 2008.

[26] J. Luo, "An analysis of the problems of fracture at new great drop line pipe," Oil and Gas Storage and Transportation, pp. 10008241, 2011. 


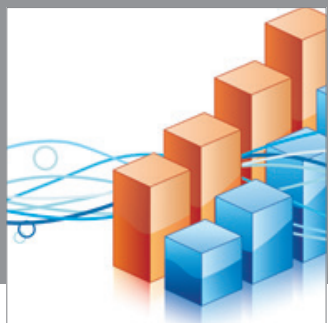

Advances in

Operations Research

mansans

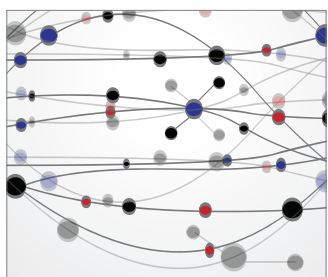

The Scientific World Journal
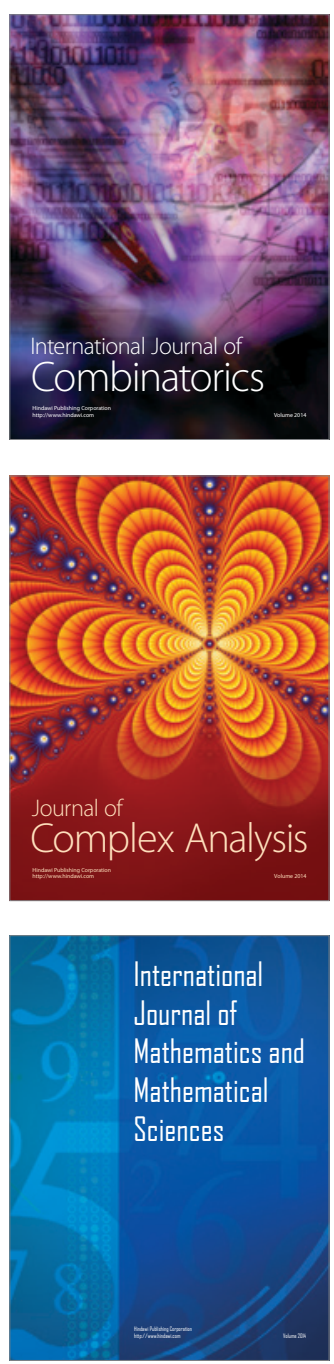
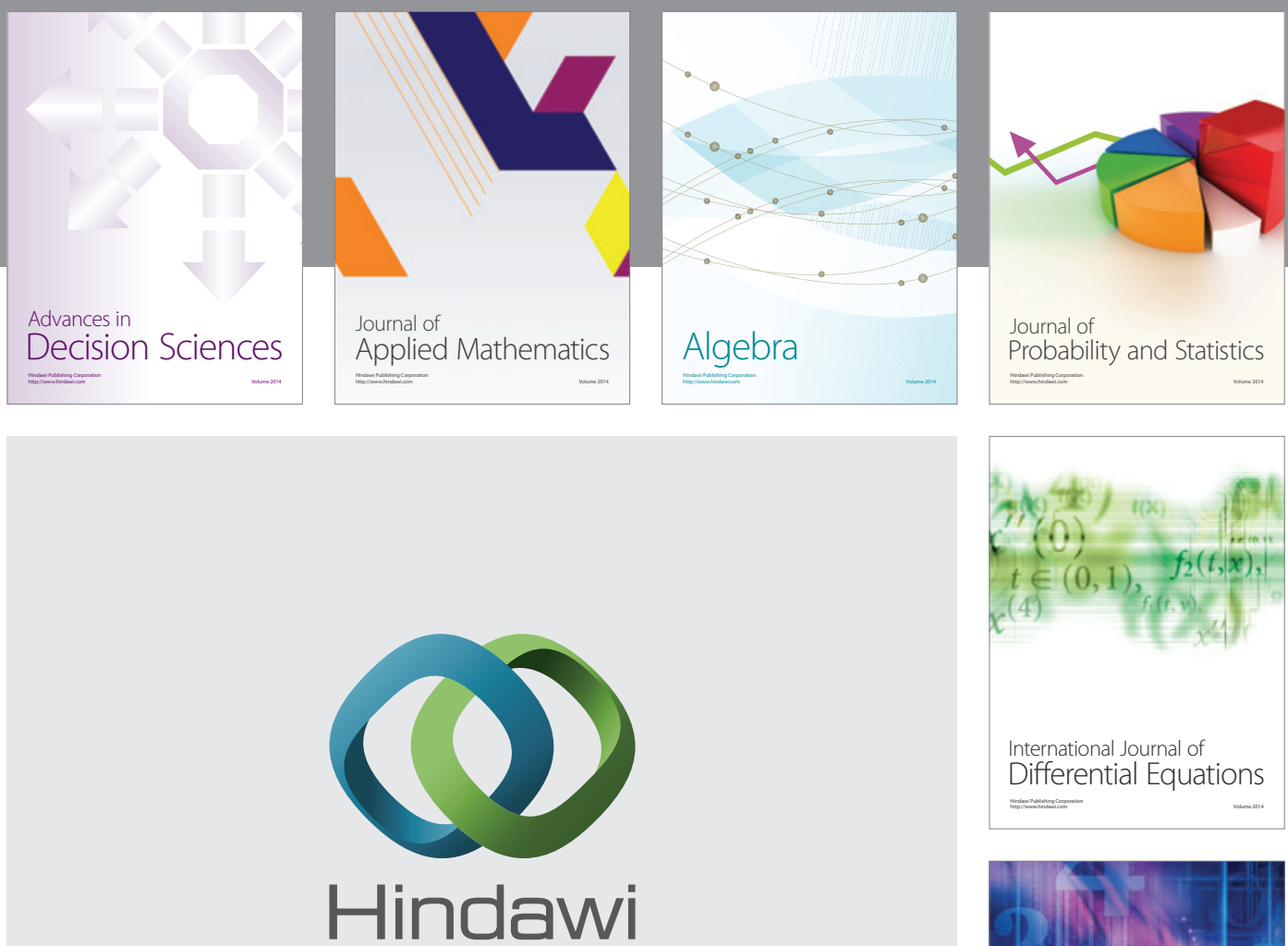

Submit your manuscripts at http://www.hindawi.com
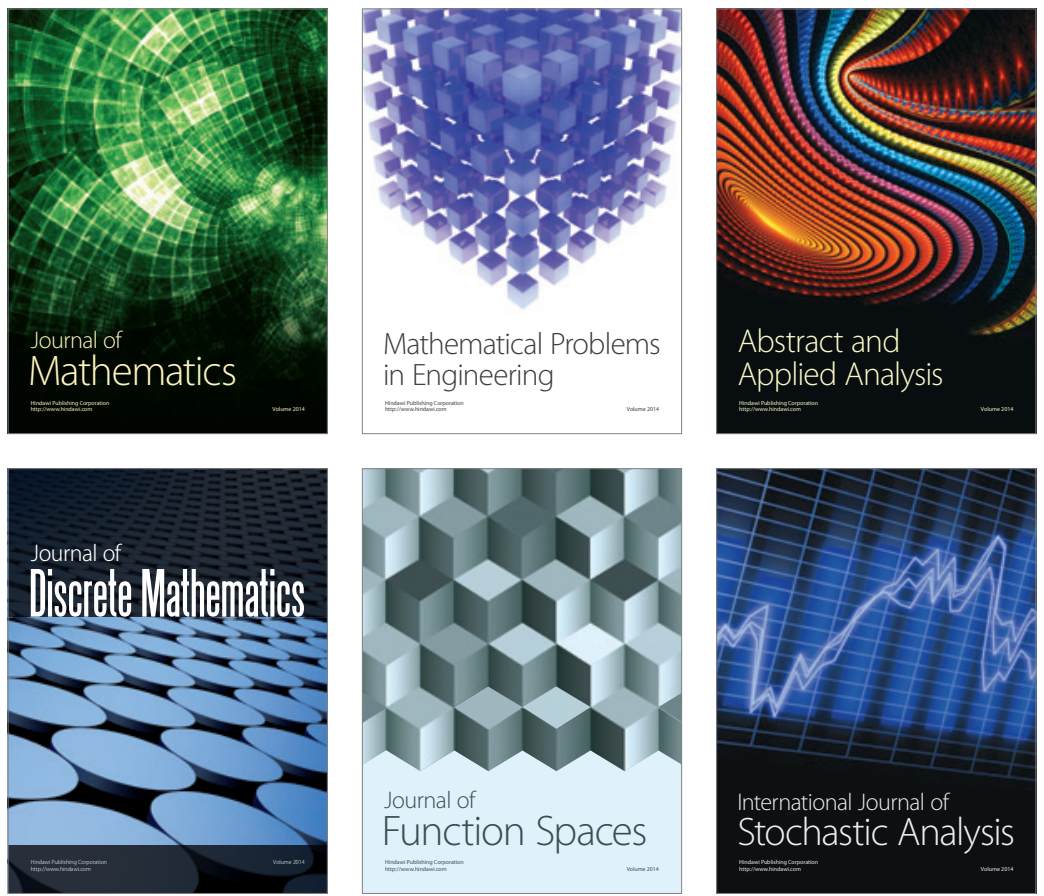

Journal of

Function Spaces

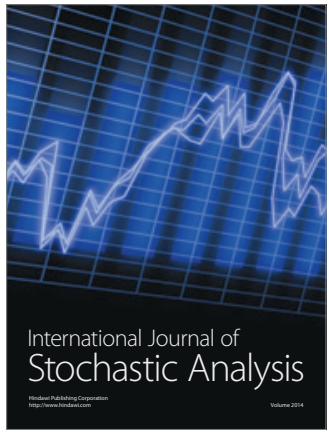

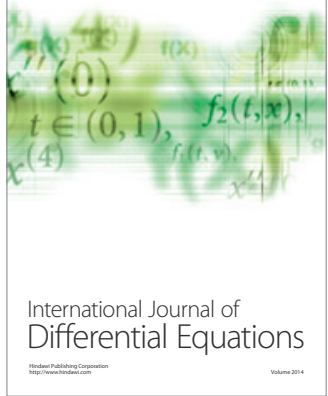
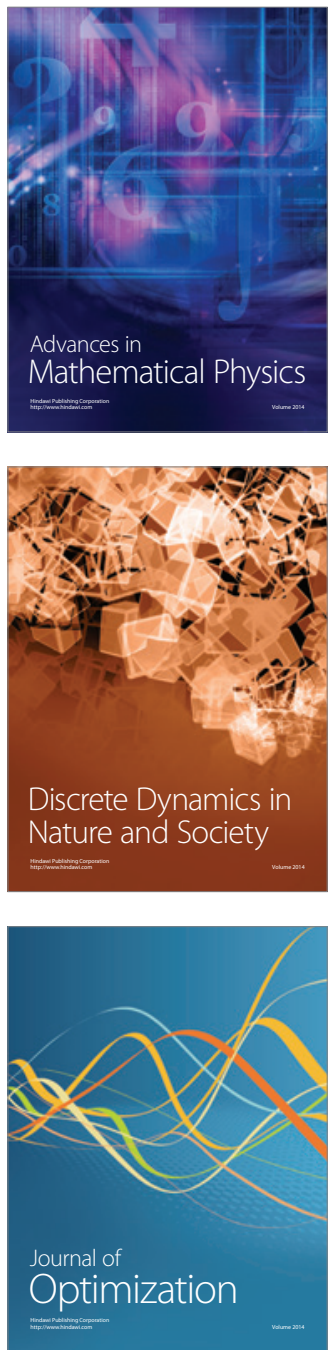